\title{
The impact of early environmental rearing condition on the discriminative stimulus effects and Fos expression induced by cocaine in adult male and female rats
}

\author{
Stephen J. Kohut • Peter G. Roma • \\ Catherine M. Davis • Gerald Zernig • Alois Saria • \\ Juan M. Dominguez • Kenner C. Rice • \\ Anthony L. Riley
}

Received: 30 April 2008 / Accepted: 2 October 2008 / Published online: 25 October 2008

(C) Springer-Verlag 2008

\begin{abstract}
Rationale A number of environmental manipulations, including maternal separation (MS), have been shown to alter behavioral responses to drugs of abuse.

Objectives This study assessed if MS affected the stimulus and Fos-inducing effects of cocaine.

Materials and methods In experiment 1, male and female Sprague-Dawley rats were exposed to brief maternal separations (BMS), long maternal separations (LMS), or animal facility rearing (AFR) and then trained as adults to discriminate cocaine $(10 \mathrm{mg} / \mathrm{kg}$, intraperitoneally) from
\end{abstract}

S. J. Kohut $(\bowtie) \cdot$ P. G. Roma $\cdot$ C. M. Davis · A. L. Riley Psychopharmacology Laboratory, Department of Psychology,

American University,

Washington, DC 20016, USA

e-mail: steve.kohut@gmail.com

J. M. Dominguez

Behavioral Neuroscience Laboratory, Department of Psychology,

American University,

Washington, DC 20016, USA

G. Zernig $\cdot$ A. Saria

Experimental Psychiatry Unit, Department of Psychiatry,

Medical University,

Innsbruck, Austria

K. C. Rice

Drug Design and Synthesis Section, Chemical Biology Research Branch, National Institute on Drug Abuse,

National Institute on Alcohol Abuse and Alcoholism,

Rockville, MD 20852, USA

Present address:

P. G. Roma

Institutes for Behavior Resources,

Baltimore, MD 21218, USA saline. Following training, generalization tests to novel doses of cocaine and other dopaminergic compounds were performed. Assessments of variations in training dose pretreatment times were also made. In experiment 2 , male and female rats exposed to MS conditions were administered cocaine or saline for 14 days, and Fos expression in the mesolimbic system was measured.

Results In males, BMS retarded the acquisition of the cocaine discrimination. Generalization to novel doses of cocaine did not differ among rearing conditions, but the training dose cue lasted longer in LMS. Distinct generalization and $\mathrm{ED}_{50}$ profiles were found between male rearing conditions for all dopamine compounds. While BMS females had higher cocaine $\mathrm{ED}_{50}$ estimates, no other differences were found in females. LMS males and females, as well as AFR females, had significant increases in Fos expression after cocaine in a region-specific manner. No differences were found with other rearing groups.

Conclusion Early environmental variables altered the stimulus effects (in a sex-dependent manner) as well as the neuronal responsiveness to cocaine, which may be mediated by the dopamine system.

Keywords Maternal separation - Discriminative-stimulus effects · Drug discrimination learning $\cdot$ Cocaine $\cdot$ Dopamine generalization · Time course $\cdot$ Immediate-early gene c-Fos

Subjective effects are considered important in drug acceptability and the likelihood of continued drug use. Drug discrimination (DD) studies have been useful as a preclinical model for studying the subjective effects of a number of psychoactive compounds from various drug classes. As a pharmacological tool, DD has demonstrated remarkable 
specificity for receptor mechanisms on which the training drug is thought to work, allowing for pharmacological characterization of the neurotransmitter system(s) involved in its discriminable effects (see Ator and Griffiths 2003; Solinas et al. 2006). DD may also be useful as an in vivo approach to studying molecular alterations in response to environmental events and how they relate to the interoceptive cue of a pharmacological challenge such as a training drug (see Colpaert 1999). Thus, just as generalization studies with selective compounds can be used to determine the subjective effects' profile of a training drug, we may be able to use this same principle to assess mechanisms responsible for alterations in the discriminative cue due to environmental challenges. A characterization of this kind may be important for determining a specific receptor's role in populations that display behaviors that are characteristic of addiction or other psychopathologies.

Early life stress models such as maternal separation (MS) have been developed in an attempt to model early adverse events in humans (e.g., abuse, neglect, etc) that have been associated with increased vulnerability to addiction (see Dube et al. 2003; Felitti et al. 1998; Teicher et al. 2006). Our initial investigation (experiment 1, described in this report) attempted to characterize responses to cocaine using a DD procedure in animals with varying degrees of MS, e.g., animal-facility-reared (AFR), brief maternal separation (BMS), and long maternal separation (LMS), during early preweaning. Given the importance of dopamine (DA) in the cocaine discriminative stimulus (see McKenna and Ho 1980; Barrett and Appel 1989; Terry et al. 1994; Katz et al. 2000), we reasoned that previously reported differences in DAergic functioning following differential rearing conditions (rats with extended separation periods show hyperdopaminergic presynaptic responses; Hall et al. 1999; see also Moffett et al. 2006b) would result in differences in the acquisition of the discrimination, with a more rapid acquisition in LMS and AFR rats (compared to BMS), as well as a leftward shift in the dose-response curve for cocaine indicative of greater sensitivity to the drug. Also, to test the relative roles of dopamine receptor subtypes in the cocaine training condition, a dopamine transporter inhibitor and a D1- and a D2like agonist were tested for generalization (or substitution) to the cocaine cue. If the reported differences in receptor binding and expression (LMS have lower DAT, $\mathrm{D}_{1}$, and $\mathrm{D}_{3}$ receptor densities, compared to BMS; see Brake et al. 2004; Meaney et al. 2002; Ploj et al. 2003) have a functional consequence in behavior elicited by cocaine, we may expect different relative roles of these subtypes in cocaine-like responses. Cue sensitivity was then further tested with a pretreatment manipulation to compare the onset and duration of cocaine's stimulus effects in animals with different MS histories. In experiment 2, cocaine- induced neuronal activation using the protein c-Fos in animals subjected to BMS, AFR, and LMS was measured in brain areas associated with the reinforcing, motor stimulating, and discriminative effects of psychostimulants (see Wise 1998; Zeng et al. 2004) to assess if any differences found in sensitivity to the discriminative cue of cocaine would be associated with differential Fos activation.

\section{Materials and methods}

\section{Subjects}

A total of 36 Sprague-Dawley rats ( $n=6 /$ rearing condition/ sex) served as subjects in experiment 1 (drug discrimination), and 42 rats $(n=6-7 /$ rearing condition/sex) served in experiment 2 (cocaine-induced Fos expression). All experimental subjects were derived from 21 primiparous females purchased from Harlan Sprague-Dawley (Indianapolis, IN, USA). All experimental manipulations took place between 1300 hours and 1600 hours in the light phase of a 12:12$\mathrm{h}$ light/dark cycle. All procedures were in compliance with National Institutes of Health and National Research Council guidelines (2003) and were approved by the Institutional Animal Care and Use Committee at American University.

\section{Maternal separation protocol}

The MS procedure used here was based on Plotsky and Meaney (1993) and described in full by Roma et al. (2008). Briefly, within $20 \mathrm{~h}$ of parturition (post-natal day [PND] 0), pups from each dam were sexed and fostered to unrelated dams. Insomuch as was possible, each foster litter was sexbalanced, and no foster litter contained more than three related pups. Foster-litter sizes ranged from 11 to 15 pups (mean \pm SD of $13 \pm 1.34$ ). Dams were then randomly assigned to foster litters of brief maternal separations, animal facility rearing (AFR; see below) or long maternal separations. As adults, the pups were then randomly assigned to be subjects in one of three experiments; two of which are presented in this report.

Starting on PND 2 and continuing through PND 14, pups in the BMS and LMS groups were removed from the maternity cages once daily and placed along the inner periphery of separate shoebox bins lined with fresh bedding resting atop a heating pad set at $32^{\circ} \mathrm{C}$. The pups remained in these conditions for either 15 (BMS group) or 180 (LMS group) min at which point they were returned to the home bin immediately followed by the dam. Dams and pups assigned to the AFR condition were briefly handled (but never separated) during twice-weekly cage cleanings (cf. Huot et al. 2001). On PND 22, all pups were weaned and 
transferred to bins (in triplets) with same-sex littermates, while the dams were transferred to individual bins and housed in a separate room. Pups remained housed in these conditions until PND 90-91, at which point they were transferred to individual hanging wire-mesh cages $(24 \times$ $19 \times 18 \mathrm{~cm}$ ). Pups for the two experiments described here were maintained in adjacent rooms.

\section{Drugs and solutions}

Cocaine hydrochloride (National Institute on Drug Abuse), GBR12909 bismesylate hydrate, SKF38393 hydrobromide, and quinpirole hydrochloride (Sigma-Aldrich) were prepared fresh daily in $0.9 \%$ saline vehicle to be administered in a volume of $2 \mathrm{ml} / \mathrm{kg}$. Doses of GBR12909 and SKF38393 were calculated as the salt. All drugs were given intraperitoneally (IP) with a 15-min pretreatment. Sodium fluoride (NaF; Sigma-Aldrich) was added to distilled water in a concentration of $312.5 \mathrm{mg} / \mathrm{ml}$ to stabilize enzymes during the blood collection phase of experiment 1 . This solution required stirring and sonication for $30 \mathrm{~min}$ before use. In experiment 2, pentobarbital (Sigma-Aldrich) was dissolved in saline at a concentration of $30 \mathrm{mg} / \mathrm{ml}$ and administered at a dose of $120 \mathrm{mg} / \mathrm{kg}$, IP.

Experiment 1: cocaine discrimination

\section{Behavioral apparatus}

Six identical operant conditioning chambers served as the experimental apparatus. Each rat was trained and tested in the same chamber throughout the study. The chambers have been described in detail elsewhere (see Kohut et al. 2007). Briefly, two empty Nalgene graduated cylinder drinking bottles were mounted $13 \mathrm{~cm}$ from each side of the centermounted food hopper. The metal lick spout was situated such that it was flush with the outer wall of the chamber. Bottle contact was detected by a drinkometer (Lafayette Instruments Model 58008). A 28-V cue light centered above the food cup was illuminated during all sessions except where noted below. All events were programmed on a desktop Dell PC connected to the boxes via a Med Associates Interface that also recorded all lick responses. A white noise generator masked extraneous sounds during all experimental sessions.

\section{Drug discrimination training}

Drug discrimination training began following 7 days of daily handling. From weaning until the initiation of training, rats were provided with sufficient food to gradually increase body weight and then maintained between 350 and $400 \mathrm{~g}$ for the remainder of the experiment.
Weights between the groups did not differ at any point during the experiment. Rats were then allowed to habituate to the experimental chambers for $1 \mathrm{~h}$ with the houselight illuminated. The center cue light was then illuminated, and the rats were trained to lick an assigned No-Drug (ND) condition bottle in the experimental chamber for food delivery (45 mg food pellet). A 1-s timeout during which the cue light became dark and bottle licks had no programmed consequences followed delivery of each pellet. The assignment of ND bottle was counterbalanced within the group so that left bottle licks were reinforced for half of the rats and right bottle licks were reinforced for the remaining subjects. Bottles were also counterbalanced across successive rats assigned to a particular experimental chamber. As rats began to lick the ND bottle, the response requirement for each pellet was increased across 20-min sessions for a final pre-drug fixed-ratio (FR) response requirement of 5. A consecutive response contingency was in effect such that licking the condition-inappropriate bottle prior to completing the response requirement on the ND bottle reset the count toward completion of the response requirement for pellet delivery to zero.

\section{Acquisition of the cocaine discrimination}

Once rats had progressed to FR5 on the ND bottle, cocaine discrimination training began. On the first cocaine day, rats were injected with $10 \mathrm{mg} / \mathrm{kg}$ cocaine (training dose) $15 \mathrm{~min}$ prior to the initiation of the experimental session. This pretreatment consisted of spending $10 \mathrm{~min}$ in the homecage and the final $5 \mathrm{~min}$ in the operant conditioning chamber (presession timeout). At the end of the pre-session timeout, the cue light was illuminated, and pellet reinforcement depended on completion of the FR contingency on the Drug (D) bottle, i.e., the bottle opposite the ND bottle. Training progressed in a double alternation sequence (i.e., D-D-ND-ND) until the FR contingency on both bottles was 10 at which time single alternations began (i.e., D-ND-D-ND).

In order for the discrimination to be considered established, the following criteria had to be met in four consecutive D and ND training sessions (either a D-NDD-ND or an ND-D-ND-D sequence). The criteria were that (a) at least $95 \%$ of all responses in a session occurred on the condition (D or ND) appropriate bottle and (b) the first completed FR10 was on the appropriate bottle. These criteria also served as training criteria for the remainder of the study. That is, rats were required to satisfy these criteria for two consecutive days after each test prior to any test session. If a rat failed to meet criteria on a training day, four consecutive days meeting the above criteria were required before another test session could be given. 


\section{Generalization testing}

During this phase, novel dose and drug tests were given. Prior to these tests, a session with the training drug vehicle (saline) and one with the training drug dose were given. Contingencies in these sessions were the same as those in the training sessions except that making ten consecutive responses on either bottle produced a food pellet. Stimulus control was demonstrated if (a) at least $80 \%$ of the total responses in the session were made on the ND bottle in the session when vehicle had been injected, (b) at least $80 \%$ of the total responses in the session were made on the $\mathrm{D}$ bottle in the session when the training dose had been injected, and (c) these results occurred in both test sessions sequentially. If control was not maintained, the performance criterion on at least four additional D and ND single-alternation training sessions had to be met before the stimulus control tests were repeated.

Novel doses of cocaine Rats were tested for generalization of a range of doses of cocaine $(0.56,1.0,3.2,5.6$, and $18 \mathrm{mg} / \mathrm{kg}$ ). Each rat was tested in a random order to control for drug history effects.

Dopaminergic compounds Rats were then tested with various doses of (in order) GBR $12909(1.0-18 \mathrm{mg} / \mathrm{kg}$; a DAT inhibitor), SKF 38393 (10-40 mg/kg; a low-affinity DA $D_{1}$ receptor agonist), and quinpirole $(0.01-0.18 \mathrm{mg} / \mathrm{kg}$; a mixed DA $\mathrm{D}_{2 / 3}$ receptor agonist). For each compound, maximal doses were determined if group rates of responding fell below 0.20 responses per second.

\section{Time course for cocaine administration}

The pretreatment manipulation was used to assess the duration of cocaine's stimulus control. The training dose $(10 \mathrm{mg} / \mathrm{kg}$, IP) was given $1,5,15,30,60$, or $120 \mathrm{~min}$ prior to the initiation of the session. In these cases, a rat was given the injection of cocaine and returned to its homecage. Only the final $5 \mathrm{~min}$ (or total duration) of the pre-session was spent in the experimental chamber. All other conditions within these test sessions were the same as described above.

\section{Plasma cocaine assessment}

Upon completion of the behavioral testing, tail blood samples were collected from these same subjects at 15 and $60 \mathrm{~min}$ post-injection of their training dose of cocaine to assess potential pharmacokinetic differences in plasma cocaine levels among rearing condition. When each blood sample was collected, $2.5 \mathrm{mg} / \mathrm{ml} \mathrm{NaF}$ was added to the whole blood, which was then centrifuged. Cocaine plasma levels were determined by tandem mass spectrometry (LC/ MS/MS) using the mass transitions $304>182 \mathrm{~m} / \mathrm{z}$ for cocaine and $313>268 \mathrm{~m} / \mathrm{z}$ for the internal standard d3methadone as described (Crespo et al. 2005).

\section{Data analysis}

One-way analysis of variance (ANOVA) with Tukey's HSD post hoc tests (where appropriate) was used to determine whether the total number of sessions to meet the performance criteria for initial testing differed among the BMS, AFR, and LMS groups for each sex. For drug discrimination test sessions, responding across bottles was calculated as the percentage of total responding on the $\mathrm{D}$ bottle, excluding responses during timeouts. If a rat failed to complete at least one FR10 during a test, cocaine-bottle responding data were removed from the analysis. Because of this criterion, higher doses of some of the dopamimetics did not contain data from the whole complement of subjects. However, at least half of the subjects in each group were used for determination of each point and most did include all subjects.

To determine generalization profiles, group means were calculated for cocaine-bottle responding at each dose. Consistent with the drug discrimination literature, full generalization was concluded if the percentage of D-bottle responding was $80 \%$ or more. Conversely, $20 \%$ or less of D-bottle responding was considered to indicate ND-like discriminative stimulus effects. Given the 95\% accuracy criterion for training session performance, these conservative thresholds can be considered significantly different from chance for a conditional discrimination (Sidman 1980; cf. Witkin et al. 1991). $\mathrm{ED}_{50}$ values (with $95 \%$ confidence limits (CL)) on cocaine-appropriate responding were determined on the linear portion of each group's doseresponse function. Two groups were considered significantly different if $95 \%$ CL were nonoverlapping. Response rates were calculated by dividing the total responses on both bottles when the cue lights were illuminated by the total session time minus timeouts and were expressed as responses per second. After response rates were determined for each dose of a given compound, values were transformed to a percent of vehicle responding and were then subjected to repeated measures ANOVA for group comparisons. During the cocaine training dose time-course manipulation, the percentage of cocaine lever responding was subjected to a repeated measures ANOVA with Bonferroni post hoc analysis. Area under the curve (AUC) was also determined for each group and analyzed with Kruskal-Wallis tests and Mann-Whitney $U$ post hocs. A $3 \times 2$ repeated measures ANOVA was performed on plasma cocaine levels with the between-subjects effect of rearing condition (LMS, BMS, AFR) and the within-subjects effect 
of time (15 or $60 \mathrm{~min})$. $\mathrm{ED}_{50}$ values and $\mathrm{AUC}$ were determined using GraphPad Prism v.5.01. All other statistical analyses were conducted using the Statistical Package for the Social Sciences, Version 13.0. All determinations of statistical significance were made at $p<0.05$.

\section{Results}

\section{Acquisition of the discrimination}

Assessment of acquisition began with the first session in which cocaine (D) was administered and ended with the last session that met acquisition criterion. An ANOVA revealed a significant effect of rearing condition in males $(F(2,14)=$ 7.615; $p=0.006$ ) with BMS rats taking significantly longer than both LMS and AFR males ( $p$ 's<0.026) to acquire the discrimination (see Fig. 1). In females, all groups acquired the discrimination in approximately the same number of sessions $(p=0.198)$.

\section{Generalization to novel doses of cocaine}

Novel doses of cocaine produced dose-dependent increases in cocaine-appropriate responding. In males, the $\mathrm{ED}_{50} \mathrm{~S}$ for AFR (3.017; 95\% CL, 2.910-3.123), BMS (3.095; 95\% CL, 2.723-3.468), and LMS (3.453; 95\% CL, 2.727-4.179) were not significantly different, and cocaine did not have an effect on rate of responding (all $p$ 's $>0.214$ ). In females, the $\mathrm{ED}_{50}$ values for BMS (5.501; 95\% CL, 4.460-6.543) rats were estimated to be higher than both AFR (3.452; 95\% CL, 3.057-3.868) and LMS (3.298; 95\% CL, 2.729-3.868). Cocaine dose dependently decreased rate of responding in all female rearing conditions $(F(5,10)=19.969 ; p<0.001)$, but there was no effect of rearing condition nor a rearing condition $\times$ dose interaction ( $p$ 's $>0.341$ ). Generalization to novel doses of cocaine in all groups is shown in Fig. 2.

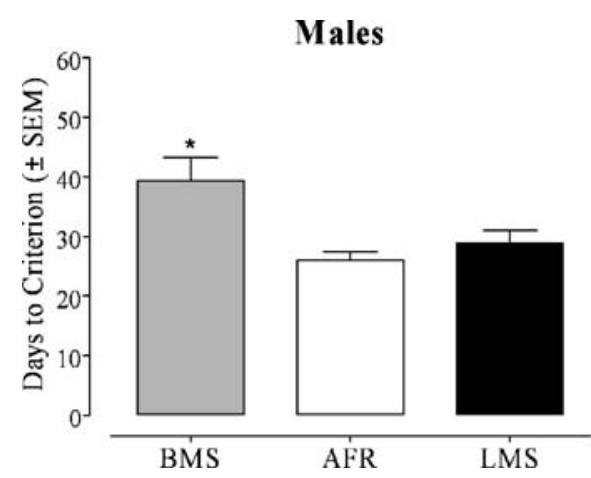

Fig. 1 Mean training sessions to reach the performance criterion for male (a) and female (b) rats in the BMS, AFR, and LMS groups. Assessment began with the first session in which D and ND sessions began alternating after FR10 had been reached and ended with the last
Time course for cocaine administration

The duration of the interoceptive cocaine cue was tested by varying the pretreatment time $(1,5,15,30,60,120 \mathrm{~min})$ of the training dose of cocaine (see Fig. 3). In males, an ANOVA revealed significant main effects of time $(F(5,70)=$ 44.630; $p<0.001)$ and rearing condition $(F(2,14)=6.676 ; p=$ $0.009)$ and a significant time $\times$ rearing condition interaction $(F(10,70)=2.045 ; p=0.041)$. Post hoc tests showed that at 60 min post-injection, LMS males displayed significantly more $\mathrm{D}$ bottle responses than BMS $(p=0.035)$, while there was a trend for significance with AFR rats (vs. LMS; $p=$ 0.064). Analysis of the AUC revealed a significant effect of rearing condition on cocaine lever responding $(H=6.34$; $p=0.042)$ with LMS being greater than both BMS $(U=$ $3.00 ; p=0.030)$ and $\operatorname{AFR}(U=5.00 ; p=0.041)$ and no difference between the latter two groups. Analysis of \% of vehicle responding showed that there was a main effect of time $(F(5,70)=5.104 ; p<0.001)$ but no main effect of rearing condition and no interaction effects with rate of responding during the pretreatment manipulation $(p$ 's $>0.176)$ for male rats. In females, the ANOVA revealed a significant main effect of time $(F(5,70)=26.601 ; p<0.001)$ but no main effect of rearing condition or significant interaction ( $p$ 's $>0.466$ ). The AUC analysis also found no differences between the rearing groups. Cocaine had a significant impact on rate of responding in female rats in a time-dependent manner $(F(5,70)=18.991 ; p<0.001)$. Rates increased over time after a suppression during shorter pretreatments, but there were no main effects of rearing condition and no time by rearing condition interaction $(p=0.296)$.

\section{Plasma cocaine concentration}

The ANOVA in males revealed a main effect of time $(F(1,13)=9.321 ; p=0.009)$ with plasma cocaine levels decreasing from 15 to $60 \mathrm{~min}$, but no main effect of rearing

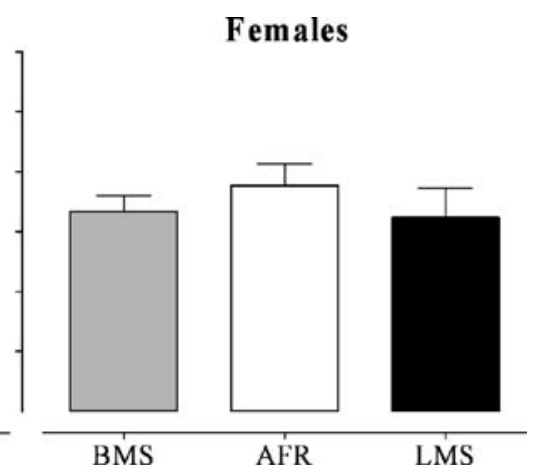

session that met criterion prior to the first training test that defined demonstration of stimulus control by the training drug. Brackets indicate the SEM. ${ }^{*} p<0.05$ compared to LMS and AFR groups 

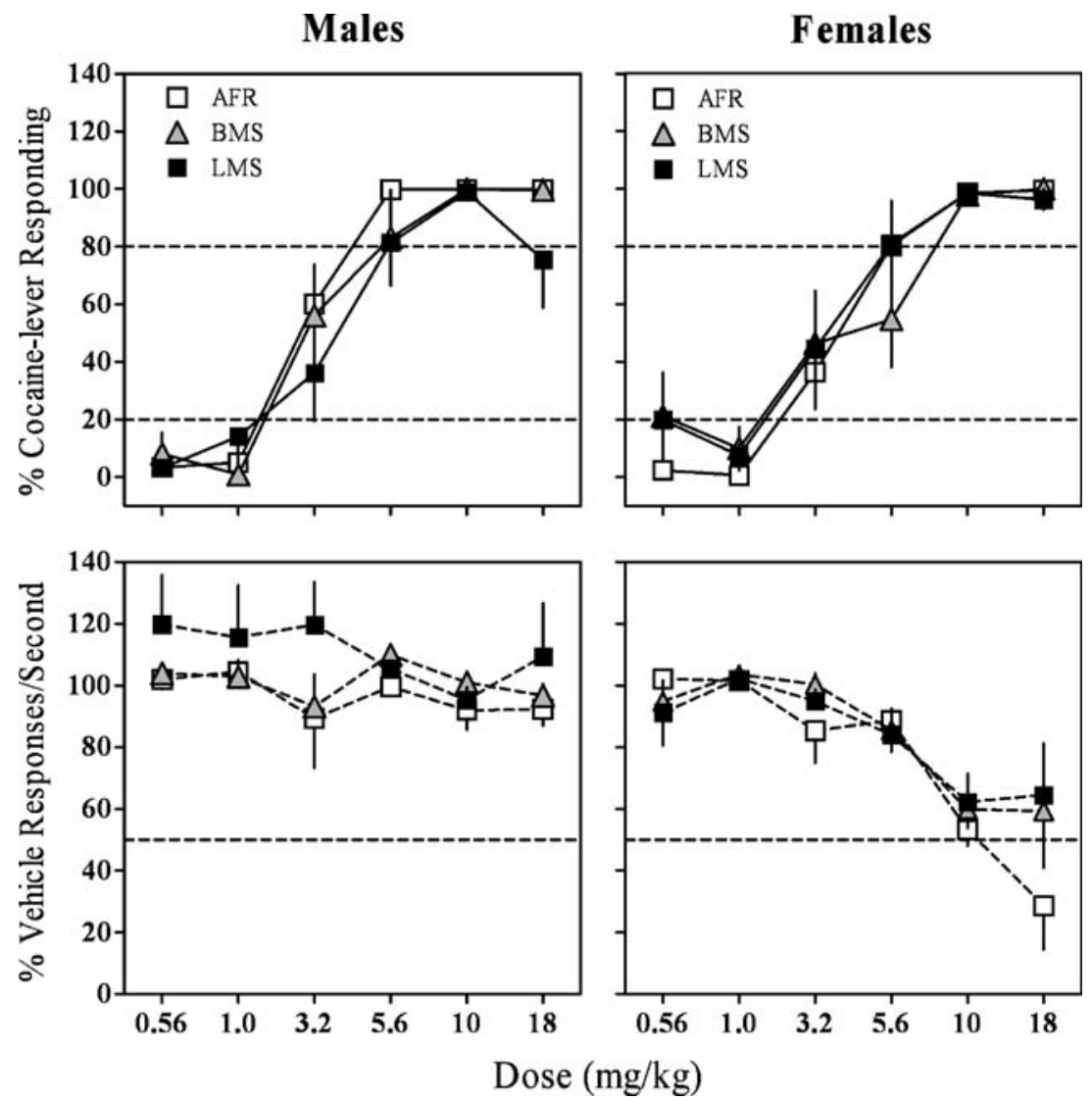

Fig. 2 Substitution (top panels; solid lines) and percentage of vehicle response rate (bottom panels; dashed lines) effects to novel doses of cocaine in male (left column) and female (right column) BMS, AFR,

and LMS reared rats trained to discriminate $10 \mathrm{mg} / \mathrm{kg}$ cocaine, IP from saline. Each data point represents the mean \pm SEM of six rats

Fig. 3 Time-course evaluation of the discriminative effects of $10 \mathrm{mg} / \mathrm{kg}$ cocaine substitution (top panels; solid lines) and response rates (bottom panels; dashed lines) in male and female rats trained to discriminate $10 \mathrm{mg} / \mathrm{kg}$ cocaine from saline. Sessions began $1,5,15,30,60$, and 120 min post-injection. Each data point represents the mean \pm SEM of five to six rats ${ }^{*} p<0.05$, different from BMS group, Tukey's HSD test. Insert: Area under the curve (AUC) during the time-course evaluation in BMS (grey), AFR (white), and LMS (black) rats. ${ }^{*} p<0.05$, Mann-Whitney U test
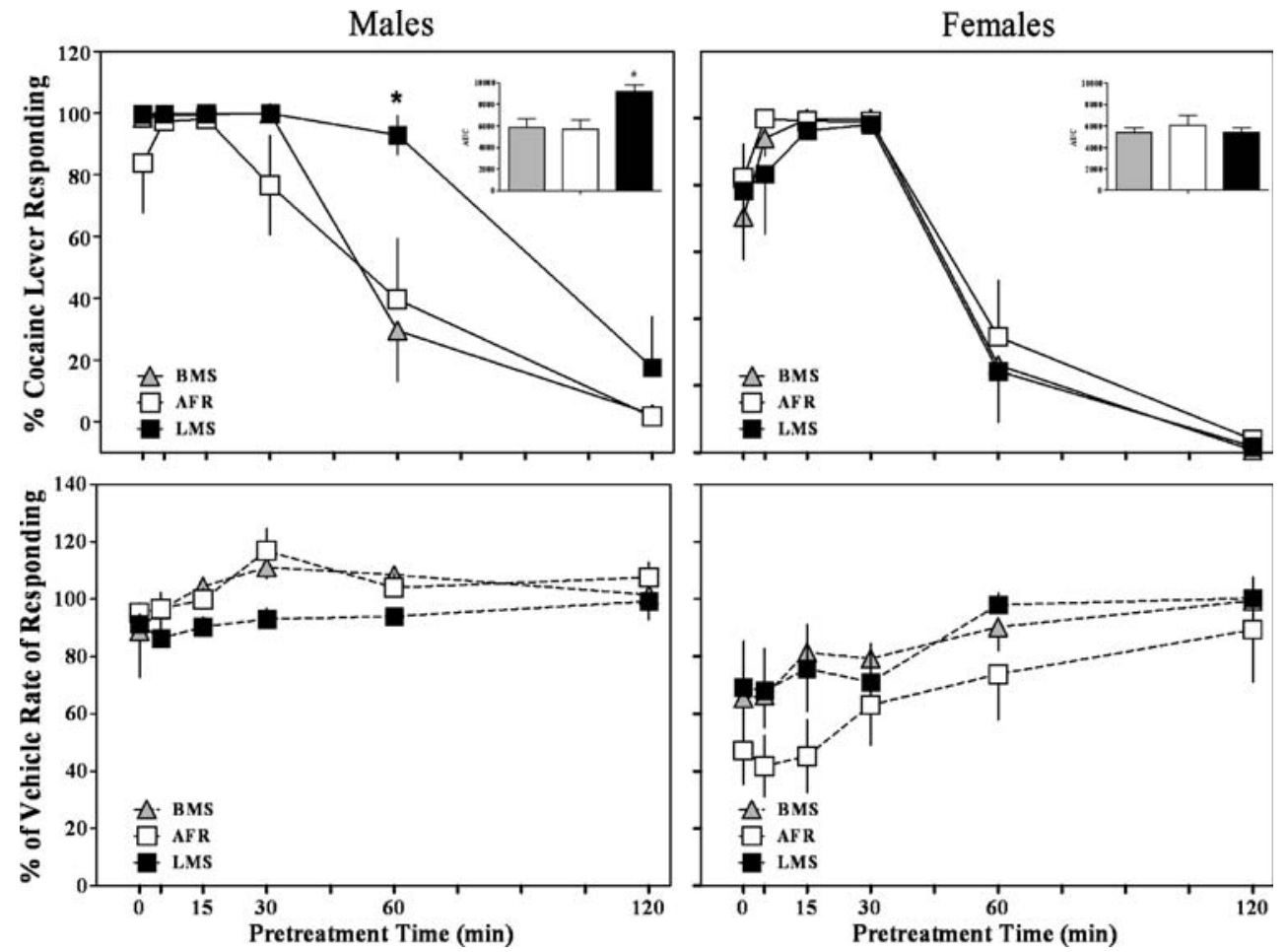
Table 1 Plasma cocaine (nanograms per milliliter) time profiles determined by tandem mass spectrometry (LC/MS/MS) for male and female adult rats exposed to BMS, AFR, or LMS rearing as pups

\begin{tabular}{|c|c|c|c|c|c|c|}
\hline & \multicolumn{2}{|l|}{ BMS } & \multicolumn{2}{|l|}{ AFR } & \multicolumn{2}{|l|}{ LMS } \\
\hline & 15 & 60 & 15 & 60 & 15 & 60 \\
\hline Males & $376.6(122.5)$ & $352.8(155.0)$ & $921.3(212.8)$ & $431.8(147.9)$ & $537.4(368.4)$ & $310.0(216.6)$ \\
\hline Females & $265.7(109.4)$ & $394.8(293.1)$ & $30.5(30.5)$ & $161.8(71.2)$ & $112.8(88.2)$ & $295.7(157.0)$ \\
\hline
\end{tabular}

Data shown as mean \pm SEM

condition and no rearing condition by time interaction ( $p$ 's $>0.092$ ); see Table 1. In females, there were no significant main effects and no significant interaction ( $p$ 's $>0.507)$. It should be noted that the high variability in our samples is likely due to the IP route of injection, which tends to result in cocaine being absorbed at a more variable rate than other routes (i.e., subcutaneous, intravenous; Gerald Zernig, unpublished data). The IP injections may also explain the lack of time effect in females, as an IP injection of cocaine has been shown to produce peak plasma after $4 \mathrm{~h}$ in the rat

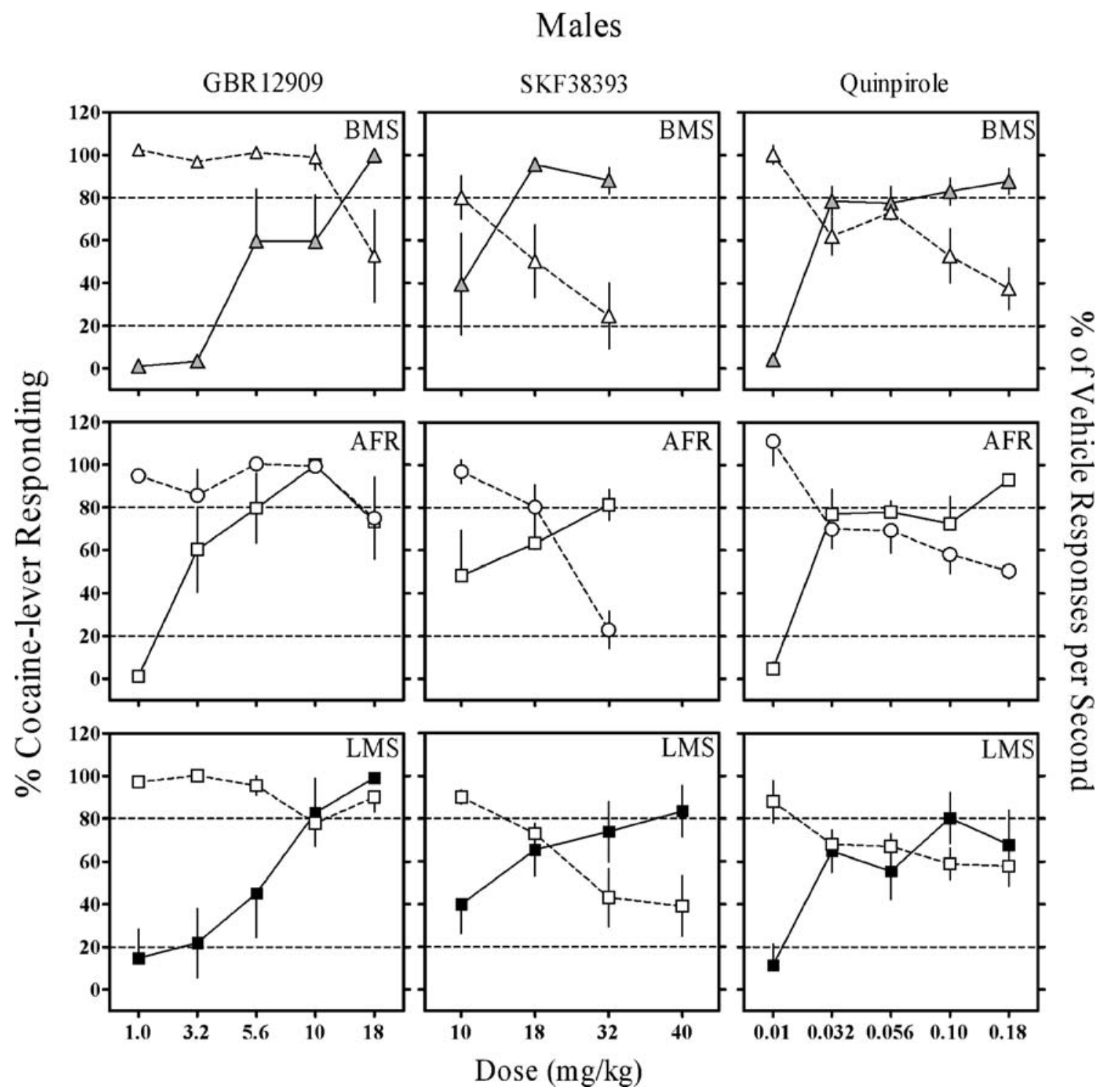

Fig. 4 Substitution (solid lines) and percentage of vehicle response rate (dashed lines) in male BMS (top row), AFR (middle row), and LMS (bottom row) reared rats tested with GBR12909 (left column),
SKF38393 (middle column), and quinpirole (right column). Each data point represents the mean \pm SEM of four to six rats 
(Misra et al. 1974), with an elimination half-life $\left(t_{1 / 2}\right)$ of 48 $60 \mathrm{~min}$ (Nayak et al. 1976), thus a slow absorption but long $t_{1 / 2}$ with local vasoconstrictor effect of cocaine.

Generalization to direct and indirect dopamine agonists

The ability of selective dopaminergic ligands to engender cocaine-appropriate responding is illustrated in Figs. 4 (males) and 5 (females), with $\mathrm{ED}_{50}$ values shown in Table 2. In males, all compounds produced dose-dependent increases in cocaine-appropriate responding. The dopamine transporter inhibitor, GBR12909, produced distinct $\mathrm{ED}_{50} \mathrm{~S}$ in each rearing condition. The rank order of $\mathrm{ED}_{50} \mathrm{~S}$ was AFR $<$ LMS $<$ BMS. This difference was also reflected in the generalization curve to different doses of GBR12909. AFR males showed overall greater levels of cocaine-like responding at nearly all doses. While the two lowest doses $(1.0-3.2 \mathrm{mg} / \mathrm{kg}$ ) produced saline responding in BMS and LMS rats, AFR rats produced partial cocaine responding with full cocaine-like responding at the three highest doses. Full generalization was achieved in LMS at the two highest doses $(10-18 \mathrm{mg} / \mathrm{kg}$ ) and in BMS at the highest dose only. Maximal levels of cocaine-like responding were equivalent in each rearing condition (maximal cocaine responding shown in Table 2). GBR12909 dose dependently decreased rate of responding $(F(4,56)=4.920 ; p=0.002)$. There was a significant rearing condition $\times$ dose interaction $(F(8,56)=$ 2.208; $p=0.040$ ) but no main effect of rearing condition $(p=0.940) . \mathrm{ED}_{50}$ values for responding with SKF38393 were estimated to be greater in LMS compared to BMS and

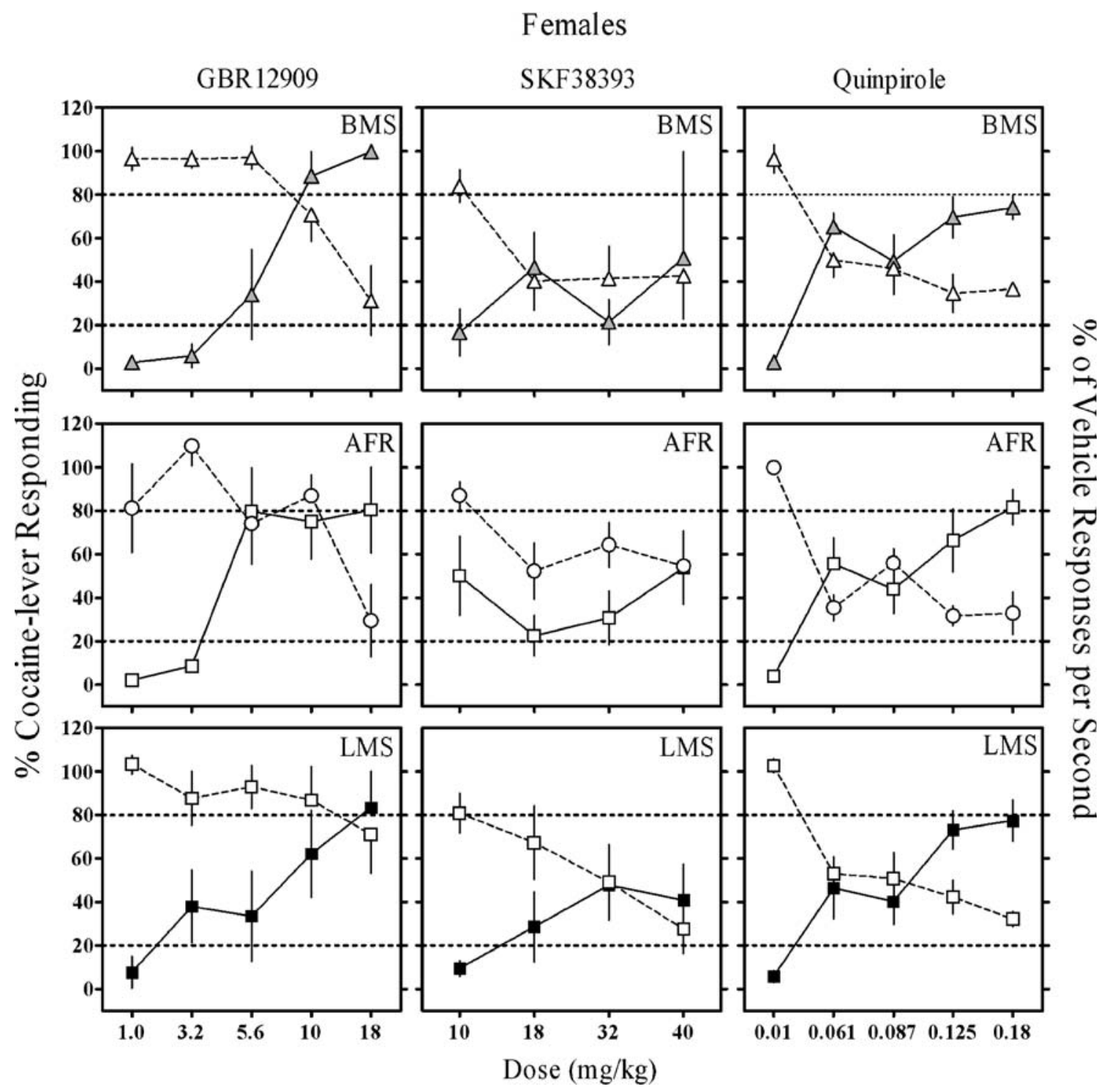

Fig. 5 Substitution and percentage of vehicle response rate in female BMS, AFR, and LMS reared rats tested with GBR12909, SKF38393, and quinpirole. All other details as in Fig. 4 
Table $2 \mathrm{ED}_{50}$ values and maximum cocaine-appropriate $(10 \mathrm{mg} / \mathrm{kg}$ training dose) responding obtained for substitution tests of direct and indirect dopamine agonists in adult male and female rats exposed to brief maternal separations (BMS), animal facility rearing (AFR), or long maternal separations (LMS)

\begin{tabular}{|c|c|c|c|}
\hline & BMS & AFR & LMS \\
\hline \multicolumn{4}{|l|}{ Males } \\
\hline \multicolumn{4}{|l|}{ ED50 values } \\
\hline DAT-GBR12909 & $9.832(8.34-11.33)^{\mathrm{a}}$ & $3.023(2.19-3.86)$ & $5.683(4.93-6.44)^{\mathrm{b}}$ \\
\hline $\mathrm{D}_{1}$-SKF38393 & $10.19(9.19-11.18)$ & $10.03(7.85-12.21)$ & $17.72(15.94-19.50)^{\mathrm{b}}$ \\
\hline $\mathrm{D}_{2}$-Quinpirole & $0.050(0.037-0.064)$ & $0.051(0.036-0.065)$ & $0.099(0.077-0.121)^{\mathrm{b}}$ \\
\hline \multicolumn{4}{|c|}{ Maximal cocaine responding } \\
\hline DAT-GBR12909 & $99.82(0.32)$ & $99.70(0.24)$ & $99.18(0.52)$ \\
\hline $\mathrm{D}_{1}$-SKF38393 & $95.68(2.73)$ & $81.41(7.25)$ & $83.52(12.07)$ \\
\hline $\mathrm{D}_{2}$-Quinpirole & $87.77(6.13)$ & $93.00(1.42)$ & $80.33(11.89)$ \\
\hline \multicolumn{4}{|l|}{ Females } \\
\hline \multicolumn{4}{|l|}{ ED50 values } \\
\hline DAT-GBR12909 & $5.889(5.54-6.24)$ & $4.989(3.74-6.24)$ & $5.893(4.37-7.41)$ \\
\hline $\mathrm{D}_{1}$-SKF38393 & $18.06(13.14-22.99)$ & $18.54(14.09-22.98)$ & $18.40(15.29-21.51)$ \\
\hline $\mathrm{D}_{2}$-Quinpirole & $0.101(0.085-0.119)$ & $0.100(0.082-0.119)$ & $0.126(0.105-0.146)$ \\
\hline \multicolumn{4}{|c|}{ Maximal cocaine responding } \\
\hline DAT-GBR12909 & $99.64(0.31)$ & $80.28(19.72)$ & $83.39(16.61)$ \\
\hline $\mathrm{D}_{1}$-SKF38393 & $50.83(48.91)$ & $53.75(16.92)$ & $47.68(13.60)$ \\
\hline $\mathrm{D}_{2}$-Quinpirole & $74.01(15.52)$ & $81.24(8.24)$ & $77.42(9.43)$ \\
\hline
\end{tabular}

Confidence intervals for $\mathrm{ED}_{50} \mathrm{~S}$ and SEM for maximal cocaine responding are shown in parentheses

${ }^{\text {a }}$ Different from both AFR and LMS rearing conditions

${ }^{\mathrm{b}}$ Different from AFR rearing condition

AFR rats. Interestingly, the LMS group was able to be tested at a $1 / 8^{\log 10}$ unit dose higher $(40 \mathrm{mg} / \mathrm{kg})$ than the other two groups, which showed disrupted rates of responding $(<0.20$ mean responses per second) at $32 \mathrm{mg} / \mathrm{kg}$. No higher doses were tested due to potential toxicity (see Witkin et al. 1993). The generalization profiles of SKF38393 showed that all rearing conditions displayed partial generalization at $10 \mathrm{mg} / \mathrm{kg}$, while AFR and LMS rats also showed partial generalization at $18 \mathrm{mg} / \mathrm{kg}$. At 18 $32 \mathrm{mg} / \mathrm{kg}$, BMS rats showed high levels of cocaine-like responding (full substitution) reaching a maximal level of $95.68 \%( \pm 2.73 \mathrm{SEM})$. At $32 \mathrm{mg} / \mathrm{kg}$, a dose that significantly reduced rates of responding, AFR rats reached full generalization with maximal levels of cocaine responding at $81.41 \%( \pm 7.25)$. In LMS rats, full substitution was displayed at the $40 \mathrm{mg} / \mathrm{kg}$ dose only, with maximal responding at $83.52 \%( \pm 12.07)$. Although AFR and BMS rats were not able to be tested at the highest dose, there were no significant effects of group or a significant interaction ( $p$ 's $>0.352)$ with rate of responding, but SKF38393 did produce dose-dependent decreases in rates $(F(2,28)=29.750 ; p<0.001)$. Quinpirole, the mixed $\mathrm{D}_{2 / 3}$ receptor agonist, produced $\mathrm{ED}_{50} \mathrm{~S}$ that were estimated to be higher in LMS rats compared to BMS and AFR. This is also reflected in the generalization profiles where high levels of cocaine-like responding were seen in BMS and AFR rats at doses of $0.061-0.18 \mathrm{mg} / \mathrm{kg}$ (all producing
$>80 \%$ responding on the cocaine-paired bottle). LMS rats showed only partial generalization at all doses, except $0.125 \mathrm{mg} / \mathrm{kg}$ (full). Again, quinpirole dose dependently decreased the number of responses in all rearing conditions $(F(4,56)=26.124 ; p<0.001)$, but there was no effect of rearing condition and no rearing condition $\times$ dose interaction $(p$ 's $>0.2280)$.

In females, $\mathrm{ED}_{50}$ values for GBR12909 were estimated to be equivalent (see Table 2). The generalization profile shows that AFR rats produced more cocaine-like responding (5.6-18 mg/kg) with LMS more partial responding (3.2$10 \mathrm{mg} / \mathrm{kg}$ ). BMS rats showed an orderly generalization profile with maximal responding reaching $99.64 \%( \pm 0.31)$ compared to $80.28 \%( \pm 19.72)$ and $83.39 \%( \pm 16.61)$ in AFR and LMS, respectively. $\mathrm{ED}_{50}$ values with $\mathrm{SKF} 38393$ were equivalent in the female groups with maximal cocainecorrelated responding reaching approximately $50 \%$ in each group. Interestingly, all female groups were able to be tested at the highest dose of $40 \mathrm{mg} / \mathrm{kg}$ (compare with male data, above). Quinpirole produced intermediate levels of responding in all groups at doses of $0.061-0.18 \mathrm{mg} / \mathrm{kg}$. Maximal levels of cocaine responding approached $80 \%$ in all groups. Rates of responding for GBR12909 $(F(4,60)=11.547$; $p<0.001)$, SKF38393 $(F(3,33)=6.472 ; p=0.001)$, and quinpirole $(F(4,56)=88.335 ; p<0.001)$ were dose dependently decreased with no other main or interaction terms approaching significance (all $p$ 's $>0.340$ ). 
Experiment 2: cocaine-induced c-Fos expression

\section{Chronic cocaine administration}

Experiment 2 was designed to assess neuronal activity in response to repeated cocaine injections in BMS, AFR, and LMS rats. Chronic drug administration began when rats were approximately 7 months of age, which allowed for the ages of rats in experiment 2 to closely match those in experiment 1 at the time of testing with cocaine (i.e., compensating for training the discrimination). All animals were handled for 1 week prior to the initiation of drug injections, and food was restricted in order to maintain body weight in the same range as experiment 1 . Food restriction was used in order to equalize parameters as closely as possible to the drug discrimination experiment. Rats received 14 consecutive once-daily IP injections of either $10 \mathrm{mg} / \mathrm{kg}$ cocaine ( $n=4 / \mathrm{sex} /$ rearing condition) or equivolume saline vehicle ( $n=3 / \mathrm{sex} /$ rearing condition). Two hours following the final cocaine or vehicle injection, each rat was anesthetized with an IP injection of $120 \mathrm{mg} / \mathrm{kg}$ pentobarbital and perfused transcardially with $50-100 \mathrm{ml}$ of ice-cold $0.1 \mathrm{M}$ sodium phosphate buffer (PB) followed by $500 \mathrm{ml}$ of freshly prepared $4 \%$ paraformaldehyde in $0.1 \mathrm{M}$ PB ( $\mathrm{pH}$ 7.4). Their brains were removed and post-fixed in the same paraformaldehyde solution for $1 \mathrm{~h}$ before being placed in $20 \%$ sucrose and $20 \mathrm{mM} \mathrm{PB}$ and stored at $4^{\circ} \mathrm{C}$ for $72 \mathrm{~h}$ at which time the brains were sectioned.

\section{Fos-immunocytochemistry}

Thirty-five-micron coronal sections were cut using a cryostat (Leica model CM1800). They were then placed in cryoprotectant solution containing phosphate-buffered saline (PBS, pH 7.4), 30\% ethylene glycol, 30\% sucrose, and $0.02 \%$ sodium azide in $40-\mathrm{ml}$ vials and maintained at $-25^{\circ} \mathrm{C}$ until processing. During processing, free-floating sections were rinsed in PBS four times for 5 min each

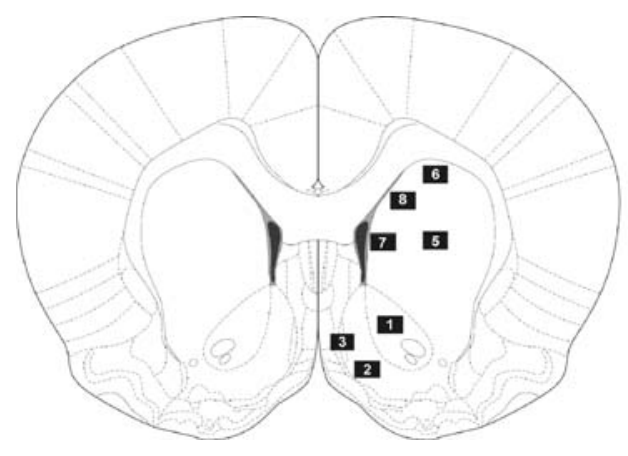

Fig. 6 Schematic diagrams of coronal sections of the rat brain (Paxinos and Watson, 2005). Fos immunoreactive nuclei were counted within the areas numbered and colored in black. Areas shown between all incubations. First, sections were blocked with $1.0 \% \mathrm{H}_{2} \mathrm{O}_{2}$ for $10 \mathrm{~min}$. The samples were transferred to PBS containing $0.4 \%$ Triton-X (Fischer Scientific) and 5\% NGS (Vector Laboratories, Burlingame, CA, USA) for 75 min to block nonspecific binding before being incubated $16 \mathrm{~h}$ at room temperature with Fos primary antibody (rabbit polyclonal IgG, Santa Cruz, CA, USA) diluted 1:5,000 in PBS containing $0.4 \%$ Triton-X and $5 \%$ NGS. Sections were then incubated for $1 \mathrm{~h}$ in biotinylated rabbit secondary antibody (1:500) and then incubated in avidin-biotinperoxidase complex (ABC Elite kit, PK-6100; Vector Laboratories) for $1 \mathrm{~h}$. Finally, sections were developed in $3,3^{\prime}$-diaminobenzidine with nickel sulfate $(2 \%$ stock solution) for approximately $7 \mathrm{~min}$, transferred into PBS for three washes before one $0.1 \mathrm{M}$ PB wash, and mounted on chrom alum/gelatin-coated slides (Fischer Scientific). Once dry, the slides were coverslipped with DPX mounting medium (EMS, Hatfield, PA, USA).

Fos-immunoreactivity (Fos-IR) was determined under a $\times 20$ objective (each area was $600 \times 400 \mu \mathrm{m}$ ) on an Olympus BX41 microscope and visualized on a Dell Optiplex GX270 desktop using a Q-Imaging Retiga 2000R camera. The areas investigated (shown in Fig. 6) were NAcc shell and core regions, the medial, dorsal, central, and dorsomedial (DM) regions of the caudateputamen $(\mathrm{CPu})$, the ventral tegmentum (VTA), and the Islands of Calleja major (ICjM) region.

\section{Data analysis}

Between-group comparisons were made using KruskalWallis tests, and a Mann-Whitney $U$ test was used to compare Fos-immunoreactivity across drug conditions (cocaine or saline) for each of the brain regions examined within each of the rearing conditions. $P$ values less than 0.05 were considered statistically significant using the Statistical Package for the Social Sciences (Version 13.0).

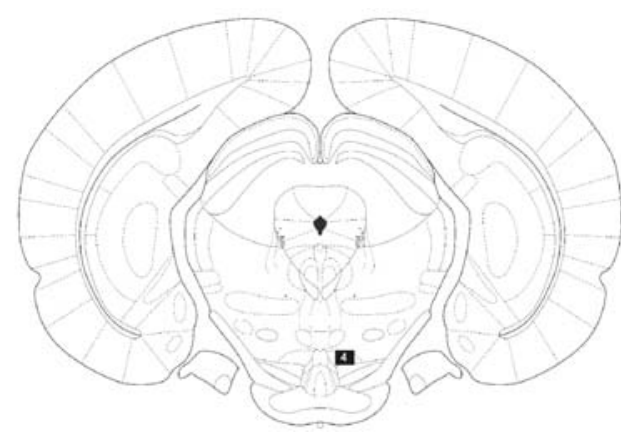

correspond in scale to the exact areas counted. Numbers indicated within black area correspond to 1 NAcc core, 2 NAcc shell, 3 ICjM, 4 VTA, $5 \mathrm{CPu}$ central, $6 \mathrm{CPu}$ dorsal, $7 \mathrm{CPu}$ medial, and $8 \mathrm{CPu} \mathrm{DM}$ 

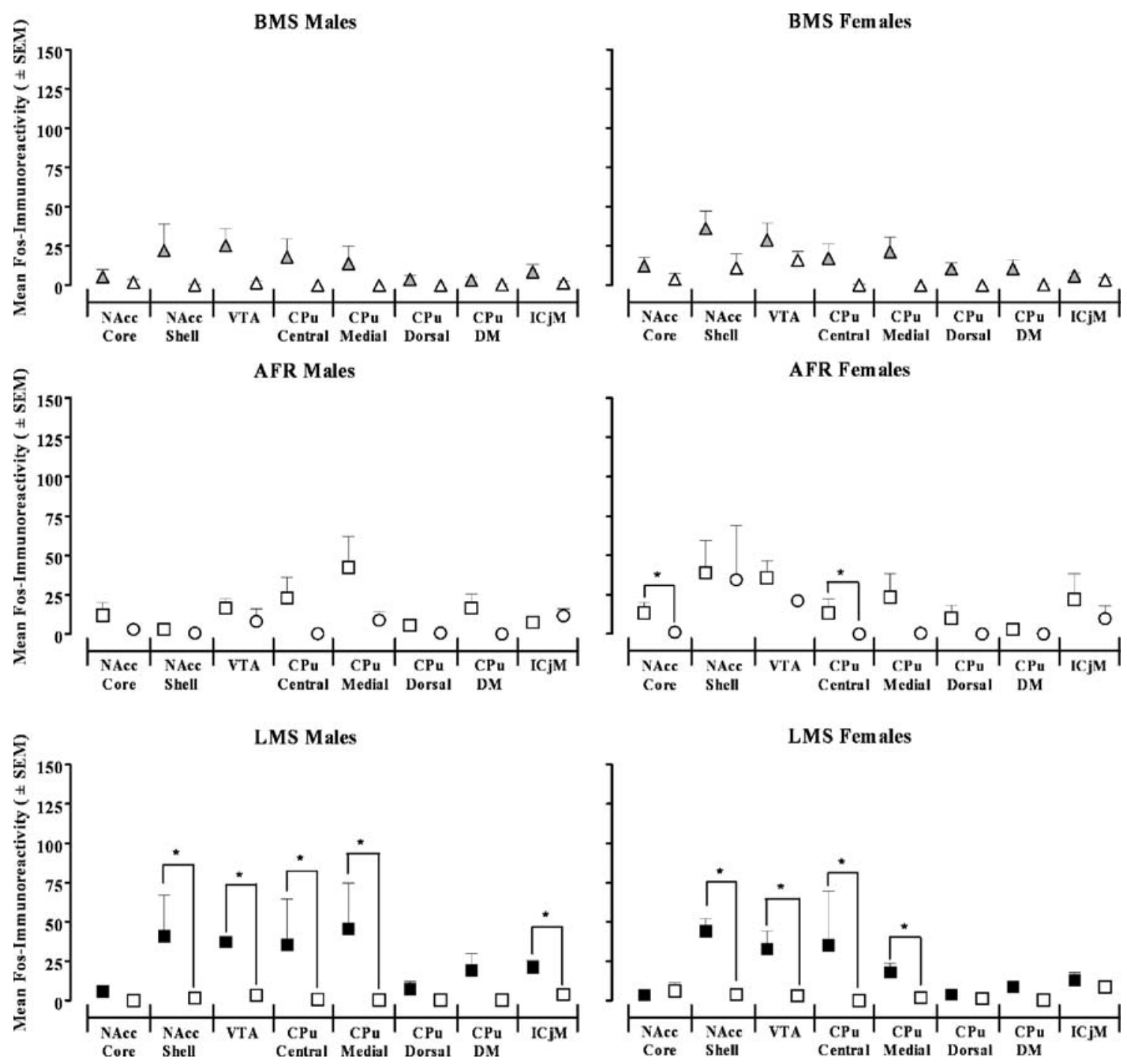

Fig. 7 Mean $( \pm$ SEM) scores of Fos immunoreactive cells in eight brain regions of male (left panels) and female (right panels) rats given 14 days of chronic cocaine or chronic saline following long maternal

separations, brief maternal separations, or animal facility rearing. Fos was counted in a $600 \times 400 \mathrm{~mm}$ area corresponding to those shown in Fig. $6 .{ }^{*} p<0.05$, cocaine vs. saline using Mann-Whitney $U$ tests

\section{Results}

Cocaine-induced Fos expression

The mean $( \pm$ SEM) numbers of labeled nuclei in each brain region after chronic cocaine and saline in animals exposed to BMS, AFR, or LMS as pups are shown in Fig. 7. Fos-IR was low in all brain regions for most of the saline-treated animals. Kruskal-Wallis tests showed that Fos-IR in both males and females did not differ among BMS, AFR, or LMS after cocaine (all $H$ 's $<5.26, p$ 's $>$ 0.072 ) or saline (all $H$ 's $<2.96, p$ 's $>0.149$ ) in any brain region examined. However, when compared with saline, the rearing conditions did show a different pattern of neuronal activation after cocaine in both males and females.

$B M S$ Cocaine- and saline-treated animals exposed to the BMS procedure displayed comparable c-Fos expression in that there were never statistically significant differences between the cocaine- and saline-treated rats in any brain region examined (all $U$ 's $>1.00, p$ 's $>.108$ ). This was true for males and females. Female BMS did, however, show a trend for significance in the medial $\mathrm{CPu}(U=0.00, p=0.076)$.

AFR AFR males showed a trend for significantly greater cFos expression (relative to saline-treated subjects) in the central and dorsomedial $\mathrm{CPu}(U=1.00, p=0.064$ and $U=$ $1.50, p=0.079$, respectively) with no other brain region approaching significance (all other brain regions $U$ 's $>2.50$, $p$ 's $>0.194)$. Chronic cocaine induced significantly greater Fos-IR in AFR females in the NAcc Core $(U=0.00, p=$ 0.046) and central $\mathrm{CPu}(U=0.00, p=0.037)$. Cocaine- and 
saline-treated females did not differ in any other brain region (all $U$ 's $>1.50, p$ 's $>0.120$ ).

LMS Male and female rats exposed to LMS showed significantly more cocaine-induced c-Fos than salinetreated subjects in the NAcc Shell (both male and female $U$ 's $=0.00, p$ 's $=0.034$ ), VTA (both male and female $U$ 's $=$ $0.00, p$ 's $=0.034$ ), medial $\mathrm{CPu}$ (males $U=4.00, p=0.032$; females $U=0.00, p=0.034$ ), and dorsomedial $\mathrm{CPu}$ (males $U=0.50, p=0.048$; females $U=0.00, p=0.031$ ). Only the LMS males showed significance in the ICjM $(U=0.00, p=0.034)$.

\section{Discussion}

As described, brief maternal separations in male rats produced a blunted response, while long maternal separations produced a heightened response to psychostimulants consistent with previous reports in other behavioral and biochemical measures (see Hall et al. 1999; Meaney et al. 2002; Weinstock et al. 1978). Decreased reactivity by BMS males was displayed in the delayed acquisition of the discrimination. It is unlikely that this delay can be attributed to learning or memory deficits, since previous studies have shown that cognitive deficits (e.g., Morris water maze performance, spatial learning, conditioned behaviors) are more likely to be displayed by LMS (Matthews et al. 1996; though see Pryce et al. 2003), and BMS may actually enhance learning and memory in some tasks (Huot et al. 2002) by playing a protective role in brain structures important for cognitive functions (Meaney et al. 1988, 1991). Evidence from the present study also may discount a learning explanation. Novel test doses of cocaine that produced both $\mathrm{D}$ and ND lever responding might be predicted to disrupt the learned behavior resulting in longer periods to meet criterion after these tests. This was not the case in that BMS, AFR, and LMS rats all met criterion relatively quickly (range, $2-10$ sessions) after novel tests with no difference in sessions to meet criterion after any dose tested (data not shown). Thus, despite being reinforced on both levers, stimulus control was maintained. Instead, a likely explanation is that blunted sensitivity to the effects of cocaine in the BMS rats may have prolonged the time to meet the acquisition criterion.

Although the generalization profile to novel doses of cocaine did not differ among rearing conditions, the timecourse manipulation showed that in males, the duration of the cocaine stimulus was longer in LMS compared to BMS and AFR rearing conditions. At 60-min post-injection, LMS rats were still responding almost entirely on the cocaineassociated bottle. This is despite the lack of plasma cocaine differences between the rearing conditions (Table 1), sug- gesting that LMS produces a heightened neuronal response to cocaine, which results in a perhaps stronger cue or longer cue duration. The increased neuronal activation in the mesolimbic system seen only in the LMS rearing condition after chronic cocaine exposure (experiment 2) may help to explain these behavioral observations. Without an acute cocaine exposed group, it is unclear whether this exaggerated response was acquired through the course of chronic injections (i.e., sensitization) or a preexisting response. However, enhanced dopamine release has been reported previously in separated rats exposed to a single amphetamine injection (Hall et al. 1999).

The role of dopamine in cocaine's discriminative effect is well documented (McKenna and Ho 1980; Terry et al. 1994; Witkin et al. 1993; Geter-Douglass and Riley 1996). Altered dopaminergic functioning may then help to explain the differences found in the cocaine characterization of male rats. Cellular and molecular studies in animals with a history of LMS have found decreases in dopamine transporter as well as $D_{1}$ and $D_{3}$ receptors relative to BMS (Meaney et al. 2002; Brake et al. 2004; Ploj et al. 2003). Enhanced $\mathrm{K}^{+}$- and psychostimulant-induced dopamine release in the NAcc of LMS rats compared to controls has also been shown (Hall et al. 1999). Studies investigating the role of DA antagonists have supported a functional role of these receptor levels in behavior (Matthews et al. 1999; Choy and Buuse 2007). Further, DA $D_{1}$ and $D_{3}$ receptors are known to regulate the induction of Fos protein in the mesolimbic system (Graybiel et al. 1990; Young et al. 1991; Zhang et al. 2004), while the dopamine transporter is central to the drug's action (Nye et al. 1995). Thus, the enhanced DA release in LMS and blunted response by BMS rats to cocaine, which when coupled with the differences in receptor levels, may lead to the differences in neuronal activation and behavioral responses to cocaine (Hooks et al. 1991; Rouge-Pont et al. 1993).

In this context, the dopaminergic contribution to the stimulus effects of cocaine differed among the male rearing conditions. BMS rats, when tested with GBR12909, had higher $\mathrm{ED}_{50}$ estimates compared to LMS reared rats. This is consistent with what others have shown in DAT densities with BMS levels being 250\% greater than LMS. Higher concentrations of cocaine would then be needed to occupy DAT binding sites and affect extracellular DA levels in BMS rats with the opposite being true for LMS. Conversely, $\mathrm{ED}_{50}$ estimates were higher in the LMS rats for the DA $\mathrm{D}_{1}$ - and $\mathrm{D}_{2}$-like compounds tested, suggesting that they were less efficacious in producing cocaine-like responding. While one might expect a greater response (evidenced by lower $\mathrm{ED}_{50}$ estimates) to stimulation of receptor systems that are downregulated as is the case with LMS rats (see above), our findings (higher $\mathrm{ED}_{50}$ estimates) in these animals may be reconciled by studies investigating the role 
of dopamine in cocaine's discriminative effects across different training doses. In a series of studies by Katz and colleagues assessing the discriminative stimulus effects of high (Witkin et al. 1991) and low (Terry et al. 1994) doses of cocaine, it was demonstrated that changes in the training dose leads to different generalization profiles by $\mathrm{D}_{1}$ and $\mathrm{D}_{2}$ receptor agonists. Specifically, at $10 \mathrm{mg} / \mathrm{kg}$ (the same dose used in the present study) partial (20-80\%) cocaine-like responding occurred with selective $\mathrm{D}_{1}$ - and $\mathrm{D}_{2}$-like compounds (including SKF38393 and quinpirole), although others have found full generalization to quinpirole at this training dose (Barrett and Appel 1989; Callahan et al. 1991; Callahan and Cunningham 1993). At a reduced training dose $(3.0 \mathrm{mg} / \mathrm{kg})$, SKF38393 and quinpirole both substitute fully for the cocaine cue. In these studies, $18 \mathrm{mg} / \mathrm{kg}$ SKF38393 was the highest dose tested. It appears then that a major factor in discriminating low vs. high doses of cocaine involves the ability of D1 agonists to elicit cocainelike responses, since full generalization has not been demonstrated in any previous study using the $10 \mathrm{mg} / \mathrm{kg}$ training dose. In the present study, BMS rats reached full generalization at $18 \mathrm{mg} / \mathrm{kg}$, and LMS rats only reached full generalization at a twofold higher dose that disrupted responding (see Table 2). This, coupled with the fact that GBR12909 was significantly less effective in eliciting cocaine responding for the BMS rearing condition, suggests that BMS-reared rats may be discriminating a functionally lower dose of cocaine compared with LMS, i.e., they are less able to detect the cocaine cue as a function of increased DAT binding sites. This interpretation should be taken with caution, however, because $\mathrm{ED}_{50}$ estimates between BMS and AFR differed only with GBR12909.

The comparison of BMS with LMS in this interpretation is not to ignore the AFR rearing condition (see below). In fact, all dopamine compounds were less effective in LMS at eliciting cocaine-like responding compared to AFR rats. The reason for this is unclear; however, one explanation may lie in the downregulation of DA receptors in LMS rats. Similar to the logic noted above, the lower DAT levels in this case may make this a functionally higher dose (see also cocaine pretreatment data, Fig. 3). If this is the case, some unknown compensatory mechanism (e.g., 5-HT or norepinephrine systems) may be playing a role in the cocaine stimulus as has been suggested with DA receptor knockout mice (Elliot et al. 2003; Chausmer et al. 2002; Katz et al. 2003). The focus on the comparisons between BMS and LMS stems from the fact that these are the most commonly used conditions represented in the MS literature. The choice of controls to which these groups are compared varies among studies. It is important to note that the groups in the present investigations (i.e., BMS, AFR, LMS) simply represent three possible rearing condition. These groups should not be thought of as producing a continuum of behavioral and biochemical responses contingent upon length of separation, but rather as individual phenotypes (cf. Jaworski et al. 2005; Moffett et al. 2006b; Table 1).

The idea of sensitized and blunted responses in LMS and BMS rats, respectively, is not a new one (Weinstock et al. 1978; Meaney et al. 2002) and is supported by many examples in the literature. For example, Moffett et al. (2006a) recently reported that LMS rats acquired cocaine self-administration at a lower dose $(0.0625 \mathrm{mg} / \mathrm{kg} /$ infusion $)$ than rats in other rearing conditions (including BMS). In fact, BMS rats did not self administer cocaine above saline levels at any dose tested. This interpretation is supported by studies of psychostimulant-induced locomotor activity in MS studies (Meaney et al. 2002; Brake et al. 2004) as well as in conditioned place preference studies (Campbell and Spear 2000) with rats exposed to short periods of neonatal isolation (a procedure similar to MS where pups are separated individually from the dam instead of as a group; see Kosten and Kehoe 2007). In females, Li et al. (2003) found that AFR rats were more responsive to cocaineinduced behavioral sensitization than both BMS and LMS reared rats. Our data with cocaine discrimination in males and females now add to the growing body of literature suggesting differences in sensitivity to the behavioral effects of drugs of abuse in differentially reared animals.

The aforementioned descriptions are in male rats. In females, rearing condition did not affect acquisition or time course of the discrimination, as all groups acquired the discrimination in the same number of sessions and showed similar cue onset and termination responding. In fact, the only behavioral difference identified among the female rearing conditions was found in the generalization profile. Here, BMS female rats had higher $\mathrm{ED}_{50} \mathrm{~S}$ compared to AFR and LMS. The dopaminergic compounds also did not produce differential responding in female rats. However, LMS females displayed greater neuronal activation (similar to LMS males) in many of the brain regions examined, while AFR females showed greater activation in two areas. The sex-dependent effects of rearing manipulation on behavioral responses to cocaine also are not surprising. In fact, many studies have found that MS produces sexspecific alterations in a number of behavioral and biochemical indices (Wigger and Neumann 1999; Slotten et al. 2006; Barna et al. 2003; McIntosh et al. 1999). The discrepancy between brain and behavior in the females is an interesting finding, nonetheless, and may be related to general differences in reactivity to cocaine between the sexes (see Becker et al. 2001). Further, differences between males and females in maternally separated rats have been demonstrated by other studies (compare Brake et al. 2004 with Li et al. 2003). More work assessing sex differences with different doses of cocaine would shed light on this phenomenon. 
The mechanisms through which the effects of MS act on drug responsivity remain unknown, and more work with molecular and cellular responses to drugs of abuse is needed to elucidate on the behavioral differences reported here and elsewhere. However, the present results do suggest that (in males) the differences reported in self-administration, conditioned place preference, and locomotor activity following psychostimulants are related to differences in both the cue strength and neuronal activation. Our data also point to the possibility that generalization/antagonism studies could be performed in dissimilar phenotypes to pharmacologically assess the functional roles of different receptors in response to drugs of abuse. The results also add to the growing body of literature suggesting that early life events can have profound and long-lasting effects on not only behavioral but also neuronal responses to repeated drug administration.

Acknowledgments The authors would like to thank Mary E. Huntsberry for her assistance on the separation procedures and Katie Rotella for her assistance with animal care. Elisabeth Ladstaetter is thanked for her expert technical assistance in the LC/MS/MS determination of the cocaine plasma levels. This work was supported by a grant from the Mellon Foundation to Anthony L. Riley and the intramural research programs of the National Institute on Drug Abuse and the National Institute on Alcohol Abuse and Alcoholism. A portion of these data was presented by SJK at the 69th and 70th annual meetings of the College on Problems of Drug Dependence. The authors have no financial conflict of interest.

\section{References}

Ator NA, Griffiths RR (2003) Principles of drug abuse liability assessment in laboratory animals. Drug Alcohol Depend 70:S55$\mathrm{S} 72$

Barna I, Balint E, Baranyi J, Bakos N, Makara GB, Haller J (2003) Gender-specific effect of maternal deprivation on anxiety and corticotropin-releasing hormone mRNA expression in rats. Brain Res Bull 62:85-91

Barrett RL, Appel JB (1989) Effects of stimulation and blockade of dopamine receptor subtypes on the discriminative stimulus properties of cocaine. Psychopharmacology 99:13-16

Becker JB, Molenda H, Hummer DL (2001) Gender differences in the behavioral responses to cocaine and amphetamine. Implications for mechanisms mediating gender differences in drug abuse. Ann Ny Acad Sci 937:172-187

Brake WG, Zhang TY, Diorio J, Meaney MJ, Gratton A (2004) Influence of early postnatal rearing conditions on mesocorticolimbic dopamine and behavioural responses to psychostimulants and stressors in adult rats. Eur J Neurosci 19:1863-1874

Callahan P, Cunningham KA (1993) Discriminative stimulus properties of cocaine in relation to dopamine D2 receptor function in rats. J Pharmacol Exp Ther 266(2):585-292

Callahan P, Appel JB, Cunningham KA (1991) Dopamine D1 and D2 mediation of the discriminative stimulus properties of $d$-amphetamine and cocaine. Psychopharmacology 103:50-55

Campbell J Spear LP (2000) Effects of early handling on amphetamine-induced locomotor activation and conditioned place preference in the adult rat. Psychopharmacology 143:183-189
Chausmer AL, Elmer GI, Rubinstein M, Low MJ, Grandy DK, Katz JL (2002) Cocaine-induced locomotor activity and cocaine discrimination in dopamine D2 receptor mutant mice. Psychopharmacology 163:54-61

Choy KHC, van den Buuse M (2007) Attenuated disruption of prepulse inhibition by dopaminergic stimulation after maternal deprivation and adolescent corticosterone treatment in rats. Eur Neuropsychopharmacol 18(1):1-13

Colpaert FC (1999) Drug discrimination in neurobiology. Pharmacol Biochem Behav 64:337-345

Crespo JA, Sturm K, Saria A, Zernig G (2005) Simultaneous intraaccumbens remifentanil and dopamine kinetics suggest that neither determines within-session operant responding. Psychopharmacology 183(2):201-209

Dube SR, Felitti VJ, Dong M, Chapman DP, Giles WH, Anda RF (2003) Childhood abuse, neglect and household dysfunction and the risk of illicit drug abuse: the adverse childhood experiences study. Pediatrics 111:564-572

Elliot EE, Sibley DR, Katz JL (2003) Locomotor and discriminativestimulus effects of cocaine in dopamine D5 receptor knockout mice. Psychopharmacology 169:161-168

Felitti VJ, Anda RF, Nordenberg D, Williamson DF, Spitz AM, Edwards et al (1998) Relationship of childhood abuse and household dysfunction to many of the leading causes of death in adults: The adverse childhood experiences (ace) study. Am J Prev Med 14:245-258

Geter-Douglass B, Riley AL (1996) Dopamine D1/D2 antagonist combinations as antagonists of the discriminative stimulus effects of cocaine. Pharmacol Biochem Behav 54(2):439-451

Graybiel AM, Moratalla R, Robertson HA (1990) Amphetamine and cocaine induce drug-specific activation of c-fos gene in striosome-matrix compartments and limbic subdivisions of the striatum. PNYAS 87:6912-6916

Hall FS, Wilkinson LS, Humby T, Robbins TW (1999) Maternal deprivation of neonatal rats produces enduring changes in dopamine function. Synapse 32:37-43

Hooks MS, Jones GH, Smith AD, Neill DB, Justice JB (1991) Response to novelty predicts the locomotor and nucleus accumbens dopamine response to cocaine. Synapse 9:121-128

Huot RL, Thrivikraman KV, Meaney MJ, Plotsky PM (2001) Development of adult ethanol preference and anxiety as a consequence of neonatal maternal separation in Long Evans rats and reversal with antidepressant treatment. Psychopharmacology 158:366-373

Jaworski JN, Francis DD, Brommer CL, Morgan ET, Kuhar MJ (2005) Effects of early maternal separation on ethanol intake, GABA receptors and metabolizing enzymes in adult rat. Psychopharmacology 181:8-15

Katz JL, Izenwasser S, Terry P (2000) Relationships among dopamine transporter affinities and cocaine-like discriminative-stimulus effects. Psychopharmacology 148:90-98

Katz JL, Chausmer AL, Elmer GI, Rubinstein M, Low MJ, Grandy DK (2003) Cocaine-induced locomotor activity and cocaine discrimination in dopamine D4 receptor mutant mice. Psychopharmcology 170:108-114

Kohut SJ, Handler SL, Hertzbach RL, Riley AL (2007) Scheduleinduced polydipsia alters cocaine- but not ethanol-induced suppression of saccharin consumption. Drug Alc Depend 91:18-25

Kosten TA, Kehoe P (2007) Early life stress and vulnerability to addiction. In: al'Absi M (ed) Stress and addiction: biological and psychological mechanisms. Academic, New York, pp 2140

Li YL, Robinson TE, Bhatnagar S (2003) Effects of maternal separation on behavioural sensitization produced by repeated cocaine administration in adulthood. Brain Res 960:42-47 
Matthews K, Hall FS, Wilkinson LS, Robbins TW (1996) Retarded acquisition and reduced expression of conditioned locomotor activity in adult rats following repeated early maternal separation: effects of prefeeding, d-amphetamine, dopamine antagonists and clonidine. Psychopharmacology 126:75-84

Matthews K, Robbins TW, Everitt BJ, Caine SB (1999) Repeated neonatal maternal separation alters intravenous cocaine selfadministration in adult rats. Psychopharmacology 141:123-134

McIntosh J, Anisman H, Merali Z (1999) Short- and long-periods of neonatal maternal separation differentially affect anxiety and feeding in adult rats: gender-dependent effects. Dev Brain Res 113:97-106

McKenna ML, Ho BT (1980) The role of dopamine in the discriminative stimulus properties of cocaine. Neuropharmacology 19:297-303

Meaney MJ, Aitken DH, van Berkel C, Bhatnagar S, Sapolsky RM (1988) Effect of neonatal handling on age-related impairments associated with the hippocampus. Science 239(1):766-768

Meaney MJ, Aitken DH, Bhatnagar S, Sapolsky RM (1991) Postnatal handling attenuates certain neuroendocrine, anatomical, and cognitive dysfunctions associated with aging in female rats. Neurobiol Aging 12(1):31-38

Meaney MJ, Brake W, Gratton A (2002) Environmental regulation of the development of mesolimbic dopamine systems: a neurobiological mechanism for vulnerability to drug abuse? Psychoneuroendocrinology 27:127-138

Misra AL, Nayak PK, Patel MN, Vadlamani NL, Mule SJ (1974) Identification of norcocaine as a metabolite of $[3 \mathrm{H}]$-cocaine in rat brain. Experientia 30:1312-1314

Moffett MC, Harley J, Francis D, Sanghani SP, Davis WI, Kuhar MJ (2006a) Maternal separation and handling affects cocaine selfadministration in both the treated pups as adults and the dams. $J$ Pharmacol Exp Ther 317:1210-1218

Moffett MC, Vicentic A, Kozel M, Plotsky P, Francis DD, Kuhar MJ (2006b) Maternal separation alters drug intake patterns in adulthood in rats. Biochem Pharmacol 73:321-330

National Research Council (2003) Guidelines for the care and use of mammals in neuroscience and behavioral research. National Academy Press, Washington, D.C.

Nayak PK, Misra AL, Mule SJ (1976) Physiological disposition and biotransformation of $[3 \mathrm{H}]$ cocaine in acutely and chronically treated rats. J Pharmacol Exp Ther 196:556-569

Nye HE, Hope BT, Kelz MB, Iadarole M, Nestler EJ (1995) Pharmacological studies of the regulation of chronic FOS-related antigen induction by cocaine in the striatum and nucleus accumbens. J Pharmacol Exp Ther 275:1671-1680

Paxinos G, Watson C (2005) The rat brain in stereotaxic coordinates, 5 th edn. Academic, San Diego

Ploj K, Roman E, Nylander I (2003) Long-term effects of maternal separation on ethanol intake and brain opioid and dopamine receptors in male Wistar rats. Neuroscience 121:787-799

Plotsky PM, Meaney MJ (1993) Early postnatal experience alters hypothalamic corticotrophin-releasing factor (CRF) mRNA, median eminence CRF content and stress-induced release in adult rats. Mol Brain Res 18:195-200
Pryce CR, Bettschen D, Nanz-Bahr NI, Feldon J (2003) Comparison of the effects of early handling and early deprivation on conditioned stimulus, context, and spatial learning and memory in adult rats. Behav Neurosci 117:883-893

Roma PG, Davis CM, Kohut SJ, Huntsberry ME, Riley AL (2008) Early maternal separation and sex differences in the aversive effects of amphetamine in adult rats. Physiol Behav 93(4 5):897-904

Rouge-Pont F, Piazza PV, Kharouby M, Le Moal M, Simon H (1993) Higher and longer stress-induced increase in dopamine concentrations in the nucleus accumbens of animals predisposed to amphetamine self-administration. A microdialysis study. Brain Res 602:169-174

Sidman M (1980) A note on the measurement of conditional discrimination. J Exp Anal Behav 33:285-289

Slotten HA, Kalinichev M, Hagan JJ, Marsden CA, Fone KCF (2006) Long-lasting changes in behavioural and neuroendocrine indices in the rat following neonatal maternal separation: genderdependent effects. Brain Res 1097:123-132

Solinas M, Panlilio LV, Justinova Z, Yasar S, Goldberg SR (2006) Using drug-discriminatin techniques to study the abuse-related effects of psychoactive drugs in rats. Nature Protocols 1:1194 1206

Teicher MH, Tomoda A, Andersen SL (2006) Neurobiological consequences of early stress and childhood maltreatment: are results from human and animals studies comparable? ANYAS 1071:313-323

Terry P, Witkin JM, Katz JL (1994) Pharmacological characterization of the novel discriminative stimulus effects of a low dose of cocaine. J Pharm Exp Ther 270:1041-1048

Weinstock M, Speiser Z, Ashkenazi R (1978) Changes in brain catecholamine turnover and receptor sensitivity induced by social deprivation in rats. Psychopharmacology 56:205-209

Wigger A, Neumann ID (1999) Periodic maternal deprivation induces gender dependent alterations in behavioral and neuroendocrine responses to emotional stress in adult rats. Phys Behav 66:293-302

Wise RA (1998) Drug-activation of brain reward pathways. Drug Alc Depend 51:12-22

Witkin JM, Nichols DE, Tery P, Katz JL (1991) Behavioral effects of selective dopaminergic compounds in rats discriminating cocaine injections. J Pharmacol Exp Ther 257(2):706-713

Witkin JM, Newman AH, Nowak G, Katz JL (1993) Role of dopamine D1 receptors in the lethal effects of cocaine and a quaternary methiodide analog. J Pharmacol Exp Ther 267 (1):266-274

Young ST, Porrino LJ, Iadarola MJ (1991) Cocaine induces striatal cFos-immunoreactive proteins via dopaminergic D1 receptors. PNAS 88:1291-1295

Zeng N, Nakajima A, He J, Nitta A, Yamada K, Nabeshima T (2004) Fos expression associated with the discriminative stimulus effects of methamphetamine in rats. ANYAS 1025:236-241

Zhang L, Lou D, Jiao H, Zhang D, Wang X, Xia Y et al (2004) Cocaine-induced intracellular signaling and gene expression are oppositely regulated by the dopamine D1 and D3 receptors. J Neurosci 24:3344-3354 